\title{
Papers
}

\section{Multicentre aneurysm screening study (MASS): cost effectiveness analysis of screening for abdominal aortic aneurysms based on four year results from randomised controlled trial}

Multicentre Aneurysm Screening Study Group

\begin{abstract}
Objective To assess the cost effectiveness of ultrasound screening for abdominal aortic aneurysms. Design Primary analysis: four year cost effectiveness analysis based directly on results from a randomised controlled trial in which patients were individually allocated to invitation to ultrasound screening (intervention) or to a control group not offered screening. Secondary analysis: projection of the data, based on conservative assumptions, to indicate likely cost effectiveness at 10 years.

Setting Four centres in the United Kingdom. Screening delivered in primary care settings with follow up and surgery offered in the main hospitals Participants Population based sample of 67800 men aged 65-74 years.
\end{abstract}

Main outcome measures Mortality from and costs (screening, follow up, elective and emergency surgery) related to abdominal aortic aneurysm; cost per life year gained.

Results Over four years there were 47 fewer deaths related to abdominal aortic aneurysms in the screening group than in the control group, but the additional costs incurred were $£ 2.2 \mathrm{~m}$. After adjustment for censoring and discounted at $6 \%$ the mean additional cost of the screening programme was $£ 63.39$ ( $\$ 97.77, € 100.48)(95 \%$ confidence interval $£ 53.31$ to $£ 73.48)$ per patient. The hazard ratio for abdominal aortic aneurysm was 0.58 (0.42 to 0.78$)$. Over four years the mean incremental cost effectiveness ratio for screening was $£ 28400$ ( $£ 15000$ to $£ 146000$ ) per life year gained, equivalent to about $£ 36000$ per quality adjusted life year. After 10 years this figure is estimated to fall to around $£ 8000$ per life year gained.

Conclusions Even at four years the cost effectiveness of screening for abdominal aortic aneurysms is at the margin of acceptability according to current NHS thresholds. Over a longer period the cost effectiveness will improve substantially, the predicted ratio at 10 years falling to around a quarter of the four year figure.

\section{Introduction}

The cost effectiveness of unselective ultrasound screening for abdominal aortic aneurysms in older men is uncertain. Previous estimates have been based on small trials ${ }^{1}$ or data from disparate sources. ${ }^{2-6}$ Results have ranged from attractive cost effectiveness ratios $^{125}$ to the conclusion that screening was on balance both harmful and costly. ${ }^{4}$

Accurate estimates of cost effectiveness are important for discretionary programmes such as screening. The multicentre aneurysm screening study (MASS) assessed the benefit of screening on mortality related to abdominal aortic aneurysms in a randomised trial. We used data from the trial to estimate the cost effectiveness of screening over the observed four year follow up period. We incorporated reliable estimates of the use of relevant resources and of unit costs appropriate to a UK policy decision. In a secondary analysis we estimated cost effectiveness over a longer period.

\section{Methods}

\section{Clinical study}

The methods for the cost effectiveness analysis build on those of the clinical study fully described elsewhere. In brief, during 1997-9, 67800 men aged 65-74 years from four centres in the United Kingdom were individually randomised to be invited for screening (intervention arm) or not (control arm). This comparison approximates to the form that a national screening programme might take compared with the current position of no routine screening. Those who attended for screening underwent ultrasonography of the abdominal aorta with a portable ultrasound machine in a primary care setting. Those found to have a normal aorta $(<3 \mathrm{~cm}$ diameter) received no further clinical follow up. Those with an aortic diameter of 3.0$4.4 \mathrm{~cm}$ were allocated to annual scans in hospital, while those with an aortic diameter of 4.5-5.4 cm were allocated to scans every three months. Men with an aneurysm with an aortic diameter $\geqslant 5.5 \mathrm{~cm}$, rapid expansion ( $\geqslant 1 \mathrm{~cm}$ within one year), or symptoms
Editorials by Greenhalgh and Powell and by Smith

Correspondence to: MJ Buxton

Health Economics Research Group, Brunel University,

Uxbridge,

Middlesex

UB8 3PH

martin.buxton@

brunel.ac.uk

bmj.com 2002;325:1135

The accompanying randomised trial is published simultaneously in The Lancet this week

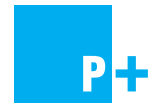

See web extra for additional material on costing methods 
attributable to the aneurysm were referred to a vascular consultant for assessment of suitability for surgery.

The clinical trial was designed to have an $80 \%$ power to detect as significant at the 5\% level a $30 \%$ reduction in deaths related to abdominal aortic aneurysms. We collected data from both arms on mortality and procedures related to abdominal aortic aneurysms, specifically elective or emergency aneurysm repairs. In the intervention arm we also collected data on attendance for screening and follow up scans and assessments for surgery.

Ethical approval for this study was obtained from the local ethics committees at each centre.

\section{Measurement of costs}

We adopted a health service perspective and calculated patient specific costs related to abdominal aortic aneurysms up to four years by applying specifically calculated unit costs of screening (invitation for screening, re-invitation to non-attenders, attendance at screening clinic, and attendance at follow up or recall clinic) and surgery (assessments for suitability, elective aneurysm repairs, and emergency surgery for rupture). (No costs were included for aneurysm ruptures that led to death without the patient being admitted to hospital for attempted emergency surgery.) All unit costs are presented on the price base of financial year 2000-1. Unless otherwise indicated, cost information was provided by the hospital finance departments of the four centres, supplemented with published information on staff hours. ${ }^{8}$

\section{Costs associated with screening}

We based screening clinic costs on the resourcing of screening for this trial and actual throughput of patients. The cost per initial invitation included clerical staff time, postage and stationery, cost of obtaining patient details, and office space and equipment. The cost per clinic attendance included clinic staff time, staff travel costs to various primary care locations, disposables, maintenance of screening equipment, charge for clinic rooms, and an annual equivalent cost for equipment. We assumed that all screening equipment had a useful life of five years. Recall scans for monitoring of the aorta involved the costs of ultrasonography, with only a few patients $(8 \%)$ seeing a consultant. We ignored the costs of any opportunistic screening that may have occurred in the control group.

\section{Costs associated with surgery}

For each of the centres we calculated the cost of an assessment for surgery based on the local procedure and standard investigations. A patient specific record of assessment before elective surgery assessments was available for screened patients; the same average number was assumed for control patients undergoing elective surgery.

To cost elective and emergency procedures we collected data for cohorts of consecutive male patients aged $\geqslant 65$ at each centre who were admitted for repair of an aortic aneurysm: 360 elective and 217 emergency. (To obtain sufficient cases to provide adequately precise cost estimates, these consecutive cohorts included patients from within the trial and others receiving surgery for abdominal aortic aneurysms who met the inclusion criteria for the trial but who were not in the screening study.) Costs were calcu- lated to include any related readmissions during the 12 months after surgery. Unless otherwise stated, we used centre specific unit costs to cost patient specific resource use.

We costed time spent in intensive care, high dependency units, and general surgical wards both before and after surgery using the appropriate hospital bed day costs inclusive of hospital overheads but exclusive of drugs, blood products, and non-pathological investigations (which were costed separately). Theatre time per patient (including any readmissions to theatre related to abdominal aortic aneurysms) was costed to allow for the time of staff involved and the theatre itself. The cost of the specific type of graft inserted during each procedure was included along with a fixed cost for consumables for each centre.

We collected detailed data on drug use for a subsample of 60 patients (emergency and elective) at one centre. We costed drugs, allowing for normal wastage and for VAT, using the British National Formulary. ${ }^{9}$ A linear regression model was used to predict hospital drug costs for all patients in the surgery sample. The total drug cost was then estimated for each patient, with allowance for purchasing discounts and overheads applicable to each hospital's pharmacy. Data on blood products issued were obtained and costed to allow for appropriate handling charges. The nonpathology investigations each patient underwent were costed using hospital specific unit costs.

For patients discharged to other hospitals and for any admissions related to abdominal aortic aneurysms within 12 months of surgery we applied bed day costs specific for specialty and for the relevant NHS trusts. ${ }^{10}$

Mean costs were calculated for each type of surgery by centre and combined. Because of the non-normal distribution of costs we used non-parametric bootstrap methods adjusted for bias to estimate confidence intervals around the mean resource use and unit costs. ${ }^{11}$ (See the appendix for full details of the costing methods.)

\section{Representation of cost effectiveness}

We measured effectiveness as survival free from mortality related to abdominal aortic aneurysms for each individual up to four years. (Such mortality included deaths from any cause within 30 days of surgery, either elective or emergency.) We expressed cost effectiveness as the incremental cost per additional life year gained and calculated $95 \%$ confidence intervals by Fieller's method..$^{12}$ The probability that screening is cost effective at four years at different values for the NHS's willingness to pay for an additional life year is represented by cost effectiveness acceptability curves. ${ }^{14}$ We have indicated the probabilities at a value of $£ 30000$, reflecting the perceived current threshold value per QALY in the United Kingdom. ${ }^{15}$

\section{Censoring and discounting}

Both for survival and costs we treated patients with less than four years' follow up and those who died from causes other than those related to abdominal aortic aneurysms as censored observations. ${ }^{16}{ }^{17}$ We used periods of six months for the analysis of censored costs. Discounting was used to reflect social time preferences and the social opportunity costs of resources. ${ }^{18}$ In the base case analysis we discounted effects in life years at the rate of $1.5 \%$ and costs at $6 \% .{ }^{19}$ 


\section{Sensitivity analysis}

We undertook sensitivity analyses to illustrate the impact of the principal aspects of uncertainty on the estimates of cost effectiveness at four years. We looked in turn at the effect of changing the value of discount rates (undiscounted and with both costs and effects discounted at $3 \%$, as proposed as the "reference case" by the US Panel on Cost-Effectiveness in Health and Medicine $^{18}$ ); costs of elective and emergency surgery (with data from the centre with the maximum and the minimum relative difference); and screening costs (arbitrary 50\% increase or decrease) or survival gain (substituting observed all cause mortality). ${ }^{7}$

\section{Projection of longer term cost effectiveness}

We undertook a secondary analysis to provide an indication of longer term cost effectiveness. Given the considerable uncertainties of life time projection we restricted this to 10 years and used conservative assumptions. For the projection we assumed that the benefit of screening is restricted to mortality related to abdominal aortic aneurysms; those for whom such deaths were prevented are subject to the same "other cause" mortality as the general population; in years 5 -10, the absolute risk reduction in such mortality accumulates at only half the rate of that observed in years 2-4, and the excess annual cost resulting from screening (recall scans and elective surgery) observed in years 2-4 continues during years 5-10.

\section{Results}

\section{Resource use and unit costs}

Table 1 shows the overall number of events observed in each arm. The initial screening of 27147 patients generated 4735 follow up or recall scans. Elective and emergency surgery occurred in both arms, with a higher rate of elective surgery $(307 v 85)$ and a lower rate of emergency surgery $(23 v 53)$ in the intervention arm. Table 1 also summarises the unit costs estimated for these observed events.

Table 2 shows further details of the estimates for the cost of elective and emergency surgery, based on consecutive cohorts of patients at the four centres. They emphasise the importance of the costs associated with any stay in intensive care, both as a proportion of the mean costs and as an explanation of the difference in cost between elective and emergency surgery. The

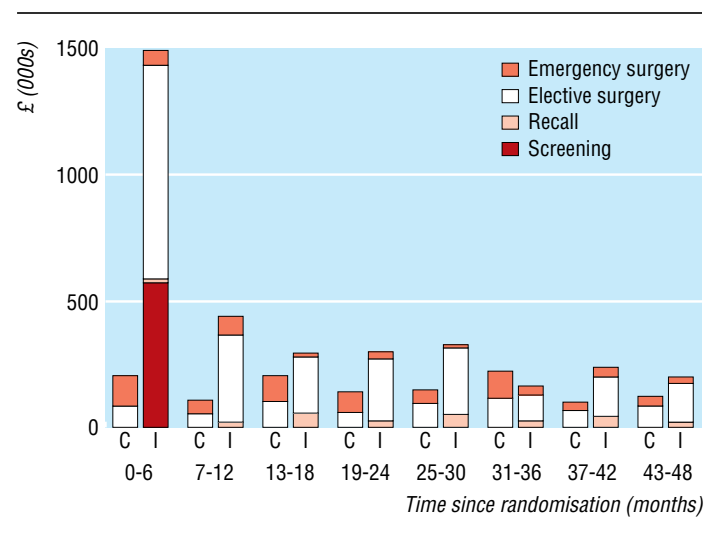

Fig 1 Costs per six month period ( $\mathrm{C}=$ control; I=intervention)

mean cost (including any related readmissions within 12 months) for elective aneurysm repair was $£ 6909$ compared with £11 176 for emergency surgery. The $95 \%$ confidence intervals around the estimates of mean resource use reflect the considerable degree of variability between patients (table 2). Table 3 shows that there may also be important differences between the centres, particularly for the cost of emergency surgery and in the magnitude of the difference in costs between the two forms of surgery.

\section{Costs of screening and surgery}

Based on the specific numbers who were invited, were re-invited, and attended for initial screen and the number of recall scans, the mean cost of screening per patient randomised in the intervention group (unadjusted for censoring) was $£ 23.23$ (table 1). The mean cost per patient randomised of all surgery related to abdominal aortic aneurysms was $£ 76.64$ in the intervention group and $£ 35.93$ in the control group. The total additional costs in the intervention group were $£ 2.2 \mathrm{~m}$ (table 1). Figure 1 shows the pattern of costs over time. Screening costs dominated in the first six month period and then there was a small ongoing cost of recalls. The costs of elective surgery in the intervention group declined over time. The costs of emergency surgery varied between periods but were consistently lower for the intervention group.

Table 1 Events and costs over four year follow up after randomisation

\begin{tabular}{|c|c|c|c|c|c|}
\hline & \multicolumn{2}{|c|}{ No of events during follow up } & \multirow[b]{2}{*}{$\begin{array}{c}\text { Cost of event } \\
\text { (£) }\end{array}$} & \multicolumn{2}{|c|}{ Total cost $(£)$} \\
\hline & $\begin{array}{c}\text { Intervention } \\
(\mathrm{n}=33 \text { 839) }\end{array}$ & $\begin{array}{c}\text { Controls } \\
(\mathrm{n}=33 \text { 961) }\end{array}$ & & Intervention & Controls \\
\hline \multicolumn{6}{|l|}{ Costs related to screening: } \\
\hline Invitation & 33839 & 0 & 1.31 & 44329 & 0 \\
\hline Re-invitation & 4602 & 0 & 1.28 & 5891 & 0 \\
\hline Initial screening & 27147 & 0 & 19.08 & 517965 & 0 \\
\hline Recall scan & 4735 & 0 & 46.04 & 217999 & 0 \\
\hline Subtotal & & & & 786184 & 0 \\
\hline \multicolumn{6}{|l|}{ Costs related to surgery: } \\
\hline Consultation before elective surgery & 695 & 131 & 309.88 & 215367 & 40594 \\
\hline Elective surgery & 307 & 85 & 6908.75 & 2120986 & 587244 \\
\hline Emergency surgery & 23 & 53 & 11175.63 & 257039 & 592308 \\
\hline Subtotal & & & & 2593392 & 1220146 \\
\hline Total $^{*}$ & & & & 3379576 & 1220146 \\
\hline
\end{tabular}

${ }^{*}$ Total cost per patient randomised: intervention group £23.23 (screening) + £76.64 (surgery)=£99.87; control group £35.93 (surgery only). 
Table 2 Breakdown of unit costs of elective and emergency surgery for aneurysm repair with $95 \%$ confidence intervals

\begin{tabular}{|c|c|c|c|c|}
\hline & \multicolumn{2}{|c|}{$\begin{array}{c}\text { Mean resource use per patient or proportion of } \\
\text { patients }\end{array}$} & \multicolumn{2}{|c|}{ Mean cost per patient $(£)$} \\
\hline & Elective $(\mathrm{n}=360)$ & Emergency $(\mathrm{n}=217)$ & Elective $(n=360)$ & Emergency $(n=217)$ \\
\hline Emergency ambulance transport to hospital & 0 & 1 & 0 & 188 \\
\hline Admission via emergency department & 0.008 & 1 & 1 & 75 \\
\hline \multicolumn{5}{|l|}{ Surgery resource use: } \\
\hline $\begin{array}{l}\text { Theatre time (overheads, capital equipment and } \\
\text { staff) (mins) }\end{array}$ & 212 (206 to 220 ) & $182(172$ to 193$)$ & 976 & 794 \\
\hline Theatre consumables & Standard cost & Standard cost & 228 & 267 \\
\hline Grafts used & 1.003 (1 to 1.01$)$ & $0.940(0.89$ to 0.96$)$ & 277 & 257 \\
\hline $\begin{array}{l}\geqslant 1 \text { readmissions to theatre during inpatient } \\
\text { episode }\end{array}$ & 0.05 (0.03 to 0.07$)$ & 0.16 (0.11 to 0.21$)$ & 44 & 169 \\
\hline \multicolumn{5}{|l|}{ Inpatient resource use: } \\
\hline Surgery and ward drugs & \multicolumn{2}{|c|}{ Estimated from subsample of 60 patients $\dagger$} & 218 & 289 \\
\hline Surgery and ward blood products & Various as used & Various as used & 379 & 927 \\
\hline Inpatient investigations & Various as used & Various as used & 118 & 175 \\
\hline Total days on ITU & 2.26 (1.97 to 2.65$)$ & 4.74 (3.88 to 5.89$)$ & 2528 & 5843 \\
\hline Total days on other wards & 11.55 (10.69 to 13.49$)$ & 7.66 (6.65 to 9.00$)$ & 1658 & 1089 \\
\hline \multicolumn{5}{|l|}{ Resource use post discharge: } \\
\hline$\geqslant 1$ discharges to another hospital & $0.08(0.05$ to 0.11$)$ & $0.16(0.11$ to 0.21$)$ & 259 & 985 \\
\hline 12 month follow up outpatient appointments & $1.87(1.81$ to 1.91$)$ & 1.24 (1.11 to 1.38$)$ & 116 & 75 \\
\hline 12 month inpatient episodes related to aneurysm & $0.05(0.03$ to 0.07$)$ & $0.05(0.02$ to 0.08$)$ & 107 & 44 \\
\hline Total mean surgery cost $(95 \% \mathrm{Cl})$ & & & $\begin{array}{c}6909 \\
(6458 \text { to } 7531)\end{array}$ & $\begin{array}{c}11176 \\
\text { (9 636 to } 13 \text { 358) } \\
\end{array}$ \\
\hline
\end{tabular}

*Details of resource use provided here (columns 2 and 3) are illustrative and form only part of information used in calculating mean costs (columns 4 and 5 ). Further details are available from corresponding author.

†Drug cost regressed against time spent in theatre and intensive care. Both variables highly significant: $R^{2}=0.62, P<0.001$

\section{Cost effectiveness at four years}

Cost effectiveness at four years is summarised in table 4. The difference between the arms of the trial in overall mean costs (after adjustment for censoring and discounting at $6 \%$ ) was $£ 63.39$ ( $£ 53.31$ to $£ 73.48$ ) per patient. Figure 2 shows the reduction in mortality related to abdominal aortic aneurysms in the intervention group compared with the control group (hazard ratio $0.58,0.42$ to 0.78 ); the numbers of deaths up to four years were 58 and 105 , respectively. The mean survival time free from mortality related to abdominal aortic aneurysms was thus greater in the intervention group than the control group, the mean difference (after discounting at $1.5 \%$ ) being 0.82 days per patient over four years (0.16 to 1.47 days). This gives an estimated incremental cost effectiveness ratio at four years of $£ 28400$ per life year gained ( $£ 15000$ to $£ 146000)$.

\section{Sensitivity analysis}

Table 5 summarises the sensitivity analyses. The results are most sensitive to the magnitude of the clinical effect. If we use the all cause mortality results from the trial to estimate the mortality effect, the cost effectiveness ratio is halved. (The trial was not, however, powered for all cause mortality and the difference, although greater than for mortality related to abdominal aortic aneurysms, was not significant.) The results

Table 3 Mean unit costs (95\% confidence interval) of elective and emergency surgery for aneurysm repair by centre

\begin{tabular}{|c|c|c|c|c|}
\hline & \multicolumn{2}{|r|}{ Elective } & \multicolumn{2}{|r|}{ Emergency } \\
\hline & No of patients & Cost $(£)$ & No of patients & Cost (£) \\
\hline Centre A & 91 & 7437 (6528 to 8965$)$ & 62 & 9883 (7 636 to 14015$)$ \\
\hline Centre B & 110 & 6813 (6 302 to 7476$)$ & 61 & 14592 (10 646 to 19795$)$ \\
\hline Centre C & 50 & $\begin{array}{c}7454 \text { (6 292 to } 10 \\
661)\end{array}$ & 29 & 8039 (6 337 to 10071$)$ \\
\hline Centre D & 109 & 6315 (5569 to 7633 ) & 65 & 10602 (8576 to 15046$)$ \\
\hline Overall & 360 & 6909 (6 458 to 7531$)$ & 217 & 11176 (9 636 to 13358$)$ \\
\hline
\end{tabular}

are relatively insensitive to alternative discount rates and to increasing or decreasing the cost differential between elective and emergency surgery by using the maximum and minimum differences (centre $\mathrm{B}$ and centre $\mathrm{C}$, respectively). The effect of decreasing or increasing the costs of screening by $50 \%$ has a greater effect (giving a cost per life year gained over four years of about $£ 23000$ and $£ 34000$, respectively). While this difference greatly exceeds our actual uncertainty about the costs of screening within the study, it illustrates the effect of more or less costly arrangements that might be implemented in a national policy. Cost effectiveness acceptability curves for the base case and these latter two sensitivity analyses are shown in figure 3 . These indicate the probabilities that screening is cost effective at four years according to willingness to pay for an

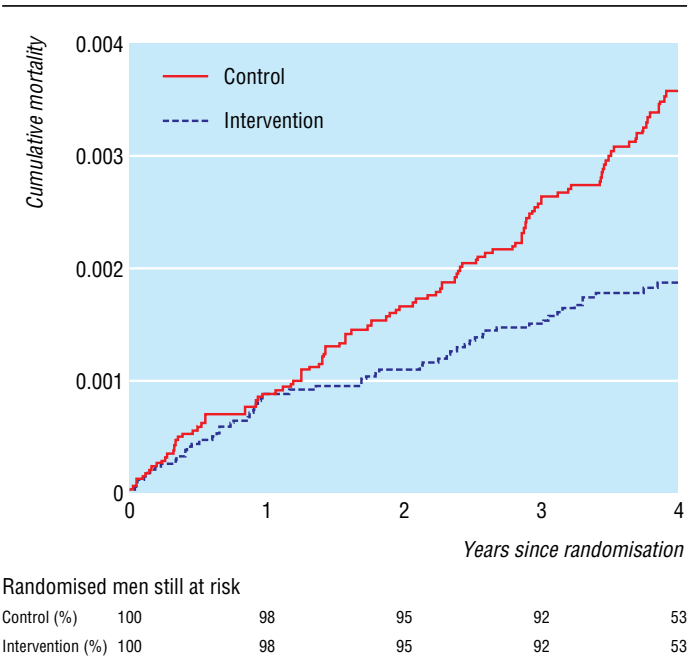

Fig 2 Mortality related to abdominal aortic aneurysms over four years of follow up by randomised group 
Table 4 Estimates of mean (SE) costs and effects to four years per patient

\begin{tabular}{lrr} 
& Intervention (n=33 839) & Controls (n=33 961) \\
\hline Costs $(£):$ & $103.67(4.41)$ & $38.22(3.32)$ \\
\hline After adjustment for censoring & $98.42(4.15)$ & $35.03(3.04)$ \\
\hline After adjustment for censoring and discounting at 6\%/year & 63.39 (53.31 to 73.48) \\
\hline Difference in costs $(95 \% \mathrm{Cl})$, after discounting & 58 & 105 \\
\hline Effects: & $1459.41(0.228)$ & $1458.54(0.271)$ \\
\hline No of deaths related to abdominal aortic aneurysm & $1394.73(0.216)$ & $1393.92(0.256)$ \\
\hline Survival time (days) & $28.82(0.16$ to 1.47) \\
\hline Survival time (days) after discounting at 1.5\%/year & $289(15281$ to 145 598)
\end{tabular}

additional life year. At $£ 30$ per life year, the probability for the base case analysis is 0.55 . It shows the extent to which this probability would increase with lower, and decrease with higher, screening costs.

\section{Projection of longer term cost effectiveness}

Over a longer period, cost effectiveness will improve substantially: those in whom death is prevented during the first four years will continue to accumulate additional life years after this time. More such deaths are expected to be prevented after four years, and the costs of follow up related to screening will increase only marginally over time. On the basis of the conservative assumptions specified above, the cost effectiveness ratio at 10 years would be around $£ 8000$ per life year saved (discounting both costs and life years).

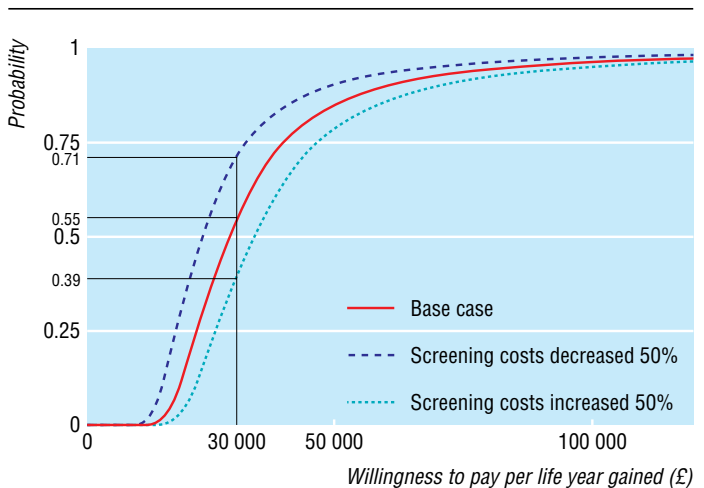

Fig 3 Cost effectiveness acceptability curves (probability that screening is cost effective after four years plotted as function of sum willing to be paid per life year gained) for base case and key sensitivity analyses, based on four years of follow up

\section{Discussion}

Cost effectiveness at four years

The clinical trial and this analysis provide firm estimates of the costs and effects up to four years of screening for abdominal aortic aneurysms. The study design may have led to some small biases resulting in conservative estimates of effect ${ }^{7}$ and cost effectiveness. Both the incremental cost and the incremental effectiveness of screening were significant, with quite narrow confidence intervals around costs. The costing combines information on patient specific events for all randomised patients with detailed costs of screening (reflecting the large scale screening experience in the trial) and of surgery (based on detailed costing of relatively large samples of elective and emergency surgery patients). The costs of elective and emergency surgery in this study were substantially higher than suggested in previous UK studies, ${ }^{2-6}{ }^{4021}$ in part reflecting the detail of analysis, the extensive samples in this study, and our inclusion of costs of any complications up to one year.

Cost per quality adjusted life year (QALY) is more useful for comparative purposes. The sampled data on mood and health status outcomes produced no evidence that screening or subsequent surgery adversely affected men's emotional states or produced significant reductions in health related quality of life or utility. ${ }^{7}$ There was no consistent pattern to suggest a clear effect of screening, surveillance, or surgery on utility. However, our results show that the average utility level of these elderly men, as with comparable populations, is around 0.8 , similar to the UK population norm for men aged $65-74 .{ }^{22}$ This implies that the estimates of cost per life year gained should be increased by a factor of $25 \%$, which would result in an

Table 5 Sensitivity analyses: survival and cost differences over four years

\begin{tabular}{|c|c|c|c|}
\hline Analysis & $\begin{array}{l}\text { Mean difference in survival } \\
\text { (days) }(95 \% \mathrm{CI})\end{array}$ & $\begin{array}{l}\text { Mean difference in cost }(£) \\
(95 \% \mathrm{Cl})\end{array}$ & $\begin{array}{l}\text { Mean cost per life year gained } \\
\text { (£) }\end{array}$ \\
\hline Base case analysis* & 0.82 (0.16 to 1.47$)$ & 63.39 (53.31 to 73.48) & 28389 \\
\hline \multicolumn{4}{|l|}{ Discount rates: } \\
\hline Undiscounted & $0.87(0.18$ to 1.56$)$ & 65.45 (54.63 to 76.27 ) & 27523 \\
\hline Effects discounted $3 \%$, costs discounted $3 \%$ & $0.76(0.14$ to 1.38$)$ & 64.40 (53.96 to 74.84$)$ & 30784 \\
\hline \multicolumn{4}{|l|}{ Surgery costs: } \\
\hline As for centre B (maximum difference) ${ }^{*}$ & $0.82(0.16$ to 1.47$)$ & 59.86 (48.85 to 70.87$)$ & 26809 \\
\hline As for centre $\mathrm{C}$ (minimum difference) ${ }^{*}$ & $0.82(0.16$ to 1.47$)$ & 69.60 (59.72 to 79.48$)$ & 31170 \\
\hline \multicolumn{4}{|l|}{ Screening costs: } \\
\hline Increased by $50 \%$ * & $0.82(0.16$ to 1.47$)$ & 74.88 (64.73 to 85.04$)$ & 33534 \\
\hline Decreased by $50 \%{ }^{*}$ & $0.82(0.16$ to 1.47$)$ & 51.91 (41.89 to 61.93$)$ & 23249 \\
\hline Survival gain based on all cause mortality* & $1.70(-1.92$ to 5.33$)$ & 62.48 (52.71 to 72.25$)$ & 13393 \\
\hline
\end{tabular}

${ }^{*}$ Includes discounting effects at $1.5 \%$ and costs at $6 \%$. 


\section{What is already known on this topic}

Small trials have suggested that an ultrasound screening programme to detect abdominal aortic aneurysms in older men may be effective

There is uncertainty about the cost effectiveness of routine screening, with widely varying estimates

\section{What this study adds}

A cost effectiveness analysis of data from a large randomised trial with follow up over four years showed 47 fewer deaths and additional costs of $£ 2.2 \mathrm{~m}$ in the group invited to screening

The adjusted net cost per patient was $£ 63.39$ and per life year gained was $£ 28400$

The projected cost per life year gained after 10 years was $£ 8000$, which is substantially lower than the perceived NHS threshold value

estimated cost per QALY for the base case analysis of about $£ 36000$. The equity implications of this adjustment need to be carefully considered.

\section{Longer term effectiveness}

It is clear from our projection that an analysis based on results to four years only will underestimate the longer term cost effectiveness substantially. The survival advantage from the 47 fewer deaths related to abdominal aortic aneurysms up to four years will continue to generate additional life years after four years. It is reasonable to assume that those in whom such deaths are prevented will be subject to similar rates of death from other causes as the general population..$^{23-25}$ The generally adverse cardiovascular risk factors of people with abdominal aortic aneurysms will be offset by the fact that those deemed fit for and surviving elective surgery will be a selected subgroup with a more favourable risk profile.

Additionally, it is to be expected that further deaths related to abdominal aortic aneurysms will be prevented after four years-that the survival curves will continue to diverge. The projection assumed that this benefit would accrue at only half the rate during years 5-10 compared with years 2-4. This is conservative because among those screened as normal the rate of rupture and the risk of developing an aneurysm that expands to $>5.5 \mathrm{~cm}$ are extremely low over this timescale. ${ }^{26} 27$

On the basis of these assumptions, the projected cost effectiveness ratio at 10 years is estimated to be $£ 8000$ per life year saved. The improvement largely stems from the accumulating life years gained for those in whom death related to abdominal aortic aneurysm was prevented during the first four years of the trial. The calculation is relatively insensitive to the rather more speculative assumptions made about the level of increasing benefit and the longer term accumulation of excess costs. That the cost effectiveness of screening will be much more favourable over the longer term is incontrovertible, and the cost effectiveness acceptability curves in figure 3 will, with increasing follow up, move substantially to the left. However, much more elaborate modelling and sensitivity analysis is needed to assess the considerable uncertainty around our estimate of cost effectiveness at 10 years and to provide estimates over still longer time periods.

\section{Policy implications}

The policy conclusions are clear. The four year analysis shows a cost effectiveness ratio already at the margin of acceptability and the projection shows that this will fall considerably even at 10 years. The clinical analysis ${ }^{7}$ and this economic analysis of the MASS trial together provide clear evidence to support the cost effectiveness of this particular form of screening in elderly men.

We thank the men who participated in the screening programme, the screening teams for their dedication and enthusiasm, the hospital management and finance departments at the screening centres for their support and assistance, and D Kim for programming assistance.

Members of Multicentre Aneurysm Screening Study Group Writing committee: H A Ashton, M J Buxton, H E Campbell, N E Day, L G Kim, T M Marteau, R A P Scott (principal investigator), and S G Thompson. Clinical directors: P Barker, J Collin, G Morris, G Sutton, and N K Wilson. Local coordinators: S Bridgewater, P S Druce, E J Hardy, S Lodge, M Pettifer, and $\mathrm{H}$ Woronowski. Local radiologists: K Dewbury, L J Jarvis, J Langham-Brown, D Lindsell, and A Page. Health economics: M J Buxton, H E Campbell, J Colehan, and J Holland. Quality of life assessments: J Colehan, M Hankins, and T M Marteau. Statistics: E Couto, N E Day, S W Duffy, L G Kim, M Styles, S G Thompson, K A Vardulaki, and N M Walker. Mortality working party: J Collin, E J Hardy, and S Lodge. Data monitoring and ethics committee: J Cuzick, M K B Parmar (chair), C V Ruckley, and C Warlow. Independent quality assurance: G Emmett, D N Kay, and J Peake. Other staff and screening teams: M Atkinson, R Bell, G Blair, J Bradshaw, J Brombley, C Bromley, R Bonner, J Bumby, A Cannings, D Carney, F Chapman, H Crascall, E Craven, K Davies, J Deacon, J Denham, S Dooley, J Ellis, G Emmett, A Flowers, H Foy, P Frugtniet, B Gibbs, B Grove, L Gutierrez, M Hayman, K Hedger, J Holbrook, A Hoult, K Jack, J Kay, M Kesterton, S Kiddle, J Lee, D Lewis, D Littler, A Lund, L Maclean, P Marshall, D McCaffetty, K Moore, S Neville, A Norris, C Packard, J Parsons, N Paterson, S Perry, L Pickard, A Prince, J Quinnell, C Rake, S Rosser, C Scott, J C Shaw, C Saunders, F Sherrin-Jones, J Simmons, S Smeeth, A Smith, P Smylie, S Sommer, J Stevens, A Taylor, H Taylor, J Turner, L Watson, C White, P Webber, M West, E Williams, and S Young. Contributors: H A Ashton (overall coordinator) recruited personnel, set up screening, directed the coordinators, oversaw work at screening centres, collected and validated data throughout the trial, and revised the paper. $\mathrm{H} \mathrm{E}$ Campbell collected and analysed unit cost data and wrote and revised the paper. L G Kim analysed trial data and updated tables, figures, and text. M J Buxton designed the economics study, was involved in setting up, running, and advising throughout the trial, wrote and revised the paper, and is guarantor. N E Day produced power calculations, was involved in setting up, running, and advising throughout the trial, and wrote and revised the paper. R A P Scott (principal investigator) prepared the grant application, recruited staff, set up screening, was directly involved in the running and management of the trial, and wrote and revised the paper. S G Thompson supervised data management and statistical analysis of trial data and wrote and revised the paper. T M Marteau designed and directed the quality of life study, was directly involved in setting up, running, and advising throughout the trial, and wrote and revised the paper.

Funding: This trial was supported by the UK Medical Research Council and Department of Health. They had no involvement in, or control over, the running of the study, the decision to publish, or the content of this paper. $\mathrm{T}$ M Marteau was supported by the Wellcome Trust.

Competing interests: None declared.

1 Lindholt JS, Juul S, Fastin H, Henneberg EW. Hospital costs and benefit of screening for abdominal aortic aneurysms. Results from a randomised population screening trial. Eur J Vasc Endovasc Surg 2002;23:55-60. 
2 Collin J. The value of screening for abdominal aortic aneurysm by ultrasound. In: Greenholgh RM, Mamaid JA, eds. The causes and management of aneurysms. Philadelphia, PA: Saunders, 1990:447-56.

3 Frame PS, Fryback DG, Patterson C. Screening for abdominal aortic aneurysm in men ages 60 to 80 years. Ann Intern Med 1993;119:411-6.

4 Mason JM, Wakeman AP, Drummond MF, Crump BJ. Population screening for abdominal aortic aneurysm: do the benefits outweigh the costs? J Public Health Med 1993;15:154-60.

5 Law MR, Morris J, Wald NJ. Screening for abdominal aortic aneurysm J Med Screen 1994;1:110-6.

6 St Leger AS, Spencely M, McColum CN, Mossa M. Screening for abdominal aortic aneurysm: a computer assisted cost-utility analysis. Eur J Vasc Endovasc Surg 1996;11:183-90.

7 MASS Study Group. The multicentre aneurysm screening study (MASS) into the effects of screening on mortality in men: a randomised controlled trial. Lancet 2002;360:1531-9.

8 Netten A, Rees T, Harrison G. Units costs of health and social care. Canterbury: Personal Social Services Research Unit, University of Kent at Canterbury, 2001

9 British Medical Association, Royal Pharmaceutical Society of Great Britain. British national formulary. BMA, RPS, 1998 (No 35).

10 Chartered Institute of Public Finance and Accountancy. The health service financial database and comparative tool. Croydon: Institute of Public Finance, 2000.

11 Barber JA, Thompson SG. Analysis of cost data in randomised trials: an application of the non-parametric bootstrap. Stat Med 2000;19:3219-36

12 Willan AR, Lin DY. Incremental net benefit in randomised trials. Stat Med 2001;20:1563-74.

13 Heitjan DF. Fieller's method and net health benefits. Health Econ 2000;9:327-35.

14 Van Hout BA, Al MJ, Gordon GS, Rutten FF. Costs, effects and the C/Eratios alongside a clinical trial. Health Econ 1994;3:309-19.

15 Raftery J. NICE: faster access to modern treatments? Analysis of guidance on health technologies. BMJ 2001;323:1300-3.

16 Collett D. Modelling survival data in medical research. London: Chapman and Hall, 1994.
17 Lin DY, Feuer EJ, Etzioni R, Wax Y. Estimating medical costs from incomplete follow-up data. Biometrics 1997;53:419-34.

18 Gold MR, Siegel JE, Russell LB, Weinstein MC. Cost-effectiveness in health and medicine. New York: Oxford University Press, 1996.

19 National Institute for Clinical Excellence. Guidance for manufacturers and sponsors. London: NICE, 2001 (Technology Appraisals Process Series No 5).

20 Forbes JF, Brady AR, Brown LC, Fowkes FGR, Greenhalgh RM, Powell JT, et al. Health service costs and quality of life for early elective surgery or ultrasonographic surveillance for small aortic aneurysms. Lance 1998;352:1656-60

21 Jepson RG, Forbes JF, Fowkes FGR for UK Small Aneurysm Trial Participants. Resource use and costs of elective surgery for asymptomatic abdominal aortic aneurysm. Eur J Vasc Endovasc Surg 1997;14:143-8.

22 Kind P, Hardman G, Macran S. UK population norms for EQ-5D. York: University of York, 1999 (CHE Discussion Paper 172).

23 Cho JS, Gloviczki P, Martelli E, Marmsen WS, Landis ME, Cherry KJ Jr, et al. Long-term survival and late complications after repair of ruptured abdominal aortic aneurysms. J Vasc Surg 1998;27:813-9.

24 Norman PE, Semmens JB, Laurence-Brown MMD, Holman CDJ. Long term relative survival after surgery for abdominal aortic aneurysms in Western Australia: population based study. BMJ 1998;317:852-6.

25 Office for National Statistics. Interim life tables for England and Wales, men, based on the years 1998-2000. www.statistics.gov.uk (accessed 18 Sep 2002). 26 Vardulaki KA, Walker NM, Couto E, Day NE, Thompson SG, Ashton HA, et al. Late results concerning feasibility and compliance from a randomised trial of ultrasonographic screening for abdominal aortic aneurysm. Br J Surg 2002;89:861-4.

27 Couto E, Duffy SW, Ashton HA, Walker NM, Myles JP, Scott RAP, et al. Probabilities of progression of aortic aneurysms: estimates and implications for policy.J Med Screen 2002;9:40-2.

(Accepted 18 October 2002) 